\title{
Frequency of Noise Induced Hearing Loss among Traffic Wardens of Lahore
}

\author{
Salman Shahid ${ }^{1}$, Hina Majid ${ }^{2}$, Khalid Ismail ${ }^{3}$, Sohail Safdar ${ }^{4}$, Syed Bilal Hassan ${ }^{5}$ \\ ${ }^{1}$ MPH Trainee, University Institute of Public Health, University of Lahore \\ 2 Demonstrator, Department of Anatomy, Postgraduate Medical Institute, Lahore \\ ${ }^{3}$ Assistant Professor, University Institute of Public Health, University of Lahore \\ ${ }_{4}^{4}$ Associate Professor, University Institute of Public Health, University of Lahore \\ 5 Demonstrator, Faculty of Allied Health Sciences, University of Lahore
}

\begin{abstract}
A B S T R A C T
Background: Noise-induced hearing loss (NIHL) is a major cause of disability throughout the world. It is the most common irreversible job-related hazard in the world with a higher burden in the developing countries. Certain occupations are at high risk for $\mathrm{NIHL}$. Traffic wardens could be considered highly vulnerable group as they are exposed to long hours of traffic noise. The objective of this study was to determine the frequency of noise induced hearing loss among traffic wardens of Lahore city.

Material and Methods: It was a cross-sectional, descriptive study, carried out from 1st December 2018 to 31st May 2019, in which 329 traffic wardens appointed in 34 beats/sectors of Lahore city were included. Data was collected through a structured questionnaire, followed by Pure Tone Audiometry (PTA) of all the subjects.

Results: A total of 329 traffic wardens were selected for this study. Mean age of the traffic wardens was $35.35 \pm 1.21$ years. NIHL was present in $174(52.9 \%)$ traffic wardens, out of which, $138(79.3 \%)$ had mild, $32(18.4 \%)$ moderate, and $4(2.3 \%)$ had moderately severe degree of hearing loss. Among the 329 traffic wardens, 165 (50.2\%) had exposure to noise between $7 \mathrm{am}$ to $3 \mathrm{pm}$ (morning shift) and $42(12.8 \%)$ had some problem with their hearing. Only $12(3.6 \%)$ had ringing in the ears or tinnitus, $140(42.6 \%)$ wore any hearing protection during duty hours and $42(12.8 \%)$ said they had difficulty in hearing and frequently asked people to repeat themselves.

Conclusion: In this study a high frequency of noise induced hearing loss was reported among traffic wardens of Lahore city with most of them having mild to moderate degree of hearing loss.

Key words: Hearing impaired, Noise-induced hearing loss, Pure tone audiometry, Traffic wardens

Authors' Contribution: Correspondence:

1,2 Conception, synthesis, planning of research Salman Shahid

Article info:

and manuscript writing Interpretation, discussion, Email: salmanshahid95@gmail.com

Received: July 16, 2019

$3,4,5$ Active participations in data collection, data

Accepted: November 27, 2019

analysis.

Cite this article. Shahid S, Majid H, Ismail K, Safdar S, Hassan SB. Frequency of noise induced hearing loss among Traffic Wardens of Lahore. J Islamabad Med Dental Coll.2019; 8(4): 181-185.

Doi: $10.35787 /$ jimdc.v8i4.380

\section{Introduction}

Noise is defined as an unwanted sound which is unpleasant, or disruptive to hearing. ${ }^{1}$ Noise-induced hearing loss $(\mathrm{NIHL})$ is a global occupational health hazard in industrialized countries. After presbycusis, it is the second most frequentform of sensorineural hearing loss. ${ }^{2}$ Hearing impairment (Audiometric Notch) with a threshold frequency of $4000 \mathrm{~Hz}$ is the characteristic feature of onset of $\mathrm{NIHL} .^{3}$ Generally, NIHL is bilateral and in both ears demonstrates the same pattern. ${ }^{4}$

Noise is associated with many psychological problems that can contribute to stress. ${ }^{5}$ The adverse effects of noise are auditory (damage of hearing) and non-auditory such as impulsive behavior, depression, fatigue and poor concentration. ${ }^{6} \mathrm{NIHL}$ occurs due to repeated and sustained exposure to high levels of sound. Any kind of noise exposure with enough strength and time can cause $\mathrm{NIHL}{ }^{7}$
\end{abstract}


Outer hair cells $(\mathrm{OHCs})$ of cochlea are main site of hearing impairment, and their damage is irreversible. When two supporting hair cells die, their apical domain expands rapidly leading to compression of hair cell beneath its apical domain. ${ }^{8}$ Occupational Safety \& Health Association (OSHA) has set 90 decibels as time weighted average (TWA) for eight-hour daily work exposure to sound, ${ }^{9}$ while this limit is 85 decibels as per National Institute of Occupational Safety \& Health (NIOSH). ${ }^{10}$

The mechanism of damage includes accretion of the reactive oxygen genus and stimulation of the intracellular stress pathway, that leads to cell death. ${ }^{11}$ Hearing loss due to cochlear dysfunction also changes the organization of the central auditory pathway. ${ }^{12}$ Varying degrees of permanentdeafness occurs due to damage to inner ear. Occupational $\mathrm{NHHL}$ is a major cause of disability throughout the world. ${ }^{13}$ As per WHO, 360 million individuals worldwide have hearing impairment.14 In America, most common reasons of hearing impairmentfor adults are noise, earinfection and age. ${ }^{15}$

$\mathrm{NIHL}$ is one of the most common problems seen among the individuals working in noisy environment. It is a sensorineural hearing loss (SHL), which may be occupational or non-occupational. ${ }^{16}$ Vehicle noise is a main contributor. ${ }^{17}$ The rapid growth of many cities in developing countries like Pakistan increases the use and ownership of motor vehicles ${ }^{18}$, thereby increasing the level of noise pollution. ${ }^{19}$ It is a notable problem of urban areas of the country, including the populous city of Lahore. ${ }^{20}$ People residing in Lahore remain under constant threat of noise pollution. As per a survey report, on any given day in Karachi, Lahore, Peshawar, Rawalpindi and Quetta, the noise produced by vehicles is about $95 \mathrm{~dB} \pm 5 \mathrm{~dB}$, with auto rickshaw producing a noise up to $100-110 \mathrm{~dB} .21$

Among professionals, the traffic wardens are the ones who are under a constant threat of becoming hearing impaired due to heavy traffic noise in the city. ${ }^{23}$ Most of them are unaware of effects of noise on their hearing capability because it takes quite long to become overt. ${ }^{23}$ In Lahore, there are almost 3000 traffic wardens, working in three shifts of eight hours. ${ }^{24}$
The city of Lahore is divided into 34 Beats/Areas for traffic management. Two senior traffic wardens are appointed in every Beat/Sector, one in morning shift and one in evening shift. This study can be beneficial in creating awareness among traffic wardens about NIHL and necessity of precautionary measures to avoid it.

\section{Material and Methods}

It was a cross-sectional, descriptive study in which 329 traffic wardens appointed in 34 beats/sectors of Lahore city were included. Ethical approval was taken from the Institutional Review Board of University of Lahore. Written informed consent was taken from all the traffic wardens included in the study. Non probability purposive sampling technique was used. The sample size was calculated with WHO sample size calculator, taking the expected prevalence of $\mathrm{NIHL}$ in Pakistan at $69 \%{ }^{25}$, confidence interval at $95 \%$ and absolute precision at $5 \%$. The study was carried out from $1^{\text {st }}$ December 2018 to $31^{\text {st }}$ May 2019. Only male traffic wardens aged between 22 to 40 years working in this profession for at least 10 years were included. While traffic wardens having any middle ear disease like otitis media were excluded from the study. Data was collected through a structured pre-tested questionnaire, followed by Pure Tone Audiometry (PTA) of all the 329 traffic wardens and entered into computer using SPSS version 24.0. Frequencies and percentages were calculated and data was presented in tables and figures.

\section{Results}

Among 329 traffic wardens, $194(59 \%)$ were up to 35 years old while $135(41 \%)$ were more than 35 years old. The mean age of traffic wardens included in the study was $35.35 \pm 1.21$ years. About $165(50.2 \%)$ traffic wardens had exposure to noise between $7 \mathrm{am}$ to $3 \mathrm{pm}$ (morning shift), $163(49.5 \%)$ between $3 \mathrm{pm}$ to $11 \mathrm{pm}$ (evening shift) and only $1(0.3 \%)$ traffic warden had exposure to noise between $11 \mathrm{pm}$ to $7 \mathrm{am}$ (night shift) (Figure 1). 


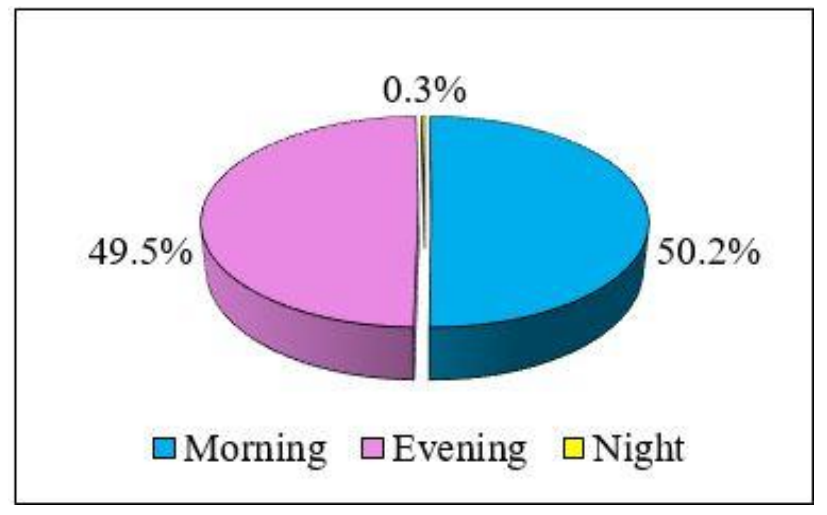

Figure 1: Distribution of traffic wardens in different shifts to noise exposure

\begin{tabular}{|c|c|c|}
\hline \multicolumn{3}{|c|}{$\begin{array}{l}\text { Table I: Epidemiological and clinical characteristics of traff } \\
\qquad \text { wardens }(n=329)\end{array}$} \\
\hline & Frequency & Percentage \\
\hline \multicolumn{3}{|l|}{ Age Groups } \\
\hline$\leq 35$ years & 194 & 59.0 \\
\hline$>35$ years & 135 & 41.0 \\
\hline Total & 329 & 100.0 \\
\hline Mean \pm SD & \multicolumn{2}{|c|}{$35.35 \pm 1.21$} \\
\hline \multicolumn{3}{|c|}{ Use of hearing protection during duty hours } \\
\hline Yes & 140 & 42.6 \\
\hline No & 189 & 57.4 \\
\hline Total & 329 & 100.0 \\
\hline \multicolumn{3}{|c|}{ NIHL according to PTA } \\
\hline Yes & 174 & 52.9 \\
\hline No & 155 & 47.1 \\
\hline Total & 329 & 100.0 \\
\hline \multicolumn{3}{|c|}{ Degree of hearing loss $(n=174)$} \\
\hline Mild & 138 & 79.3 \\
\hline Moderate & 32 & 18.4 \\
\hline Moderately severe & 4 & 2.3 \\
\hline Total & 174 & 100.0 \\
\hline
\end{tabular}

NIHL-Noise Induced Hearing Loss, PTA-Pure Tone Audiometry

Regarding hearing impairment, $42(12.8 \%)$ traffic wardens had problem with their hearing, including visit to a doctor/audiologist while majority $287(87.2 \%)$ said they did not have any problem. Only 12 wardens (3.6\%) had ringing in the ears or tinnitus, while majority $(n=317$; $96.4 \%$ ) never faced this problem. About 140 traffic wardens $(42.6 \%)$ wore hearing protection during duty hours. NIHL was not present in any of the 140 traffic wardens who wore hearing protection. Of those wardens with impaired hearing, $42(12.8 \%)$ said they frequently asked people to repeat themselves while $287(87.2 \%)$ wardens did not have such difficulty. Pure Tone Audiometry test revealed that more than half $(n=174$; $52.9 \%$ ) of the traffic wardens had noise induced hearing loss while $155(47.1 \%)$ had no NIHL. Out of those 174 traffic wardens who had noise induced hearing loss, 138 $(79.3 \%)$ had mild, $32(18.4 \%)$ had moderate while only 4 $(2.3 \%)$ traffic wardens had moderately severe hearing loss (Table I).

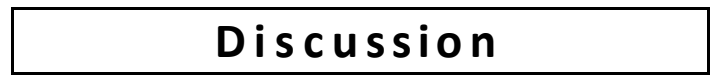

The current study was conducted to know the frequency of noise induced hearing loss among traffic wardens of Lahore city. Regarding hearing impairment, only $12.8 \%$ traffic wardens had problem with their hearing especially those in the morning or evening shifts. However, Pure Tone Audiometry test revealed that more than half $(n=174 ; 52.9 \%)$ of the traffic wardens had noise induced hearing loss with about $20 \%$ suffering from moderate to moderately severe degree of hearing loss.

Most of the traffic wardens (59\%) were up to 35 years old with a mean age of $35.35 \pm 1.21$ years. The findings of a study carried out in Ambala city (India) by Singh and coworkers (2015) were different from our study as majority of traffic wardens (78\%) were more than 35 years old. ${ }^{17}$ Similarly, another study by Venkatappa and colleagues (2018) reported that mean age of the traffic wardenswas $42.46 \pm 6.78$ years. ${ }^{23}$

Constant exposure to heavy noise is dangerous for traffic wardens especially those who work eight hours daily during morning and evening shifts, when noise level is too high. The results of this study also confirmed that almost all the traffic wardens $(99.7 \%)$ had high level of noise exposure because they were working in morning and evening shift and only one traffic warden was working in night shift when exposure to noise is low.

Only a few of the traffic wardens included in this study had problem with their hearing and visited a doctor/audiologist, with only $3.6 \%$ traffic wardens complaining of ringing in the ears or tinnitus. The results of our study exhibited a better scenario than a study carried out by Sreenivasulu who reported $40 \%$ of traffic wardens with complaint of ringing in the ears or tinnitus. ${ }^{26}$ Use of hearing protection tools during duty hours, for example, ear muffs and ear plugs prevent traffic wardens from hearing loss. It is significant to mention that $42.6 \%$ traffic wardens used hearing protection devices but such 
protective measures should be followed by all traffic wardens. Contrasting results have been reported by different researchers in this aspect. The results of a study undertaken by Singh and coworkers in Ambala India, reported only $2 \%$ traffic wardens using hearing protective equipments. ${ }^{17}$

In our study only $12.8 \%$ traffic wardens "frequently asked people to repeat themselves" due to hearing loss, while Gupta et al. found that 35.5\% traffic wardens "asked people to talk loudly" in their study. ${ }^{19}$ When noise induced hearing loss was evaluated using pure tone audiometry, $\mathrm{NIHL}$ was found prevalent among more than half of the traffic wardens $(n=174 ; 52.9 \%)$ with $79.3 \%$ having mild, $18.4 \%$ moderate and $2.3 \%$ moderately severe degree of hearing loss. In contrast, Venkatappa et al. reported only $26.7 \%$ traffic wardens with noise induced hearing loss in which $62.5 \%$ had mild and $37.5 \%$ had severe degrees of hearing loss. ${ }^{23}$ Another study carried out by Sreenivasulu showed the frequency of $\mathrm{NIHL}$ at $38.3 \%$ among traffic wardens, with $43.5 \%$ having mild, $21.7 \%$ moderate and $34.8 \%$ moderately severe degree of hearing loss. ${ }^{26}$

The limitation of the study is that many traffic wardens refused to participate in this study, therefore, it may not be representative of the general traffic warden community. Also, there may be information errors, as traffic wardens may falsely report on good habits such as use of ear protection during duty hours, and they may be misreporting on certain unacceptable habits, such as double duty shifts

\section{Conclusion}

There was a high frequency of noise induced hearing loss among traffic wardens of Lahore city with most of them having mild to moderate degree of hearing loss. Further studies should be conducted on a largescale to assess the frequency of noise induced hearing loss among traffic wardens and devise preventive strategies that are effective in the long run.

\section{References}

1. Islam MT, Nahar N, Islam MJ, Islam MA, Hossen MA. Traffic Induced Noise Pollution and its Impact on Human Health in Chittagong City Corporation. J. Environ. Sci. Nat. Resour. 2015; 8(2): 37-40. Doi: 10.3329/jesnr.v8i2.26862

2. Lavinsky J, Crow AL, Pan C, Wang J, Aaron KA, Ho MK, et al. Genome-Wide Association Study Identifies Nox3 as a Critical Gene for Susceptibility to NoiseInduced Hearing Loss. PLoS Genet. 2015; 11(4): e1005094. Doi: 10.1371/journal.pgen.1005094

3. Ristovska I, Jachova Z, Atanasova N. Frequency of the Audiometric Notch Following Excessive Noise Exposure. Arch Acoust. 2015; 40(2): 213-21. Doi: 10.1515/aoa-2015-0024

4. Maci L, Belvis AD, Assennato AC, Pagano V, Tavolar $M$. Bilateral hearing asymmetry and lateral differences in susceptibility to noise damage. Pulsus $\mathrm{J}$ of Surg Res. 2017; 1(1): 15-16.

5. Daiber A, Kröller-Schön S, Frenis K, Matthias Oelze $\mathrm{M}$, Kalinovic $\mathrm{S}$, et al. Environmental noise induces the release of stress hormones and inflammatory signaling molecules leading to oxidative stress and vascular dysfunction-Signatures of the internal exposome. Bio Factors. 2019; 45 (4): 495-506. Doi: 10.1002/biof.1506

6. Himanshu KS, Mohit SG. Are bullet riders at risk of noise induced hearing impairment? Otolaryngol Open Access J. 2018; 3(1): 000166.

7. Alvarado JC, Fuentes-Santamaría V, María Gabaldón-UII C, Juiz JM. Age-Related Hearing Loss Is Accelerated by Repeated Short-Duration Loud Sound Stimulation. Front Neurosci. 2019; 13: 77. Doi: 10.3389/fnins.2019.00077

8. Goutman JD, Elgoyhen AB, Gomez-Casati ME. Cochlear hair cells: the sound-sensing machines. FEBS Lett. 2015; 589(22): 3354-61. Doi: 10.1016/j.febslet.2015.08.030

9. Occupational Safety and Health Administration (OSHA). OSHA fact sheet: laboratory safety noise. Washington, DC: OSHA. 2011.

10. Carroll $\mathrm{YI}$, Eichwald J, Scinicariello F, Hoffman HJ, Deitchman S, Radke MS et al. Vital Signs: NoiseInduced Hearing Loss Among Adults - United States 2011-2012. MMWR. 2017; 66(5): 139-144. 10.15585/mmwr.mm6605e3 
11. Kurabi A, Keithley EM, Housley GD, Ryan AF, Wong ACY. Cellular mechanisms of noise-induced hearing loss. Hearing Res. 2017; 349: 129-37. Doi: 10.1016/j.heares.2016.11.013

12. Fetoni AR, Troiani D, Petrosini L, Paludetti G. Cochlear injury and adaptive plasticity of the auditory cortex. Front Aging neurosci. 2015; 7: 1-5. Doi: 10.3389/fnagi.2015.00008

13. Indora $V$, Khaliq $F$, Vaney $N$. Evaluation of the auditory pathway in traffic policemen. Int $\mathrm{J}$ Occup Environ Med. 2017; 8: 109-16. Doi: 10.15171/ijoem.2017.913

14. World Health Organization (WHO). WHO global estimates on prevalence of hearing loss: mortality and burden of diseases. Geneva: WHO. 2012.

15. Masterson EA, Tak S, Themann CL, Wall DK, Groenewold MR, et al. Prevalence of hearing loss in the United States by industry. Am J Ind Med. 2013; 56(6): 670-81. Doi: 10.1002/ajim.22082

16. Dhinakaran N, Karthikeyan BM. Prevalence of noise induced hearing loss among police personnel in Madurai City. Int J Adv Res. 2017; 5(8): 410-6. Doi: 10.21474//JAR01/5075

17. Singh A, Bansal A, Goel S, Goel PK, Chhikara P, Singh NK. A rapid appraisal of traffic policemen about auditory effects of traffic noise pollution from Ambala city. Med J DY Patil Univ. 2015; 8: 12-5. Doi: 10.4103/0975-2870.148826

18. Sanju HK, Kumar P. Self-assessment of noiseinduced hearing impairment in traffic police and bus drivers: questionnaire-based study. Indian J Otol. 2016; 22: 162-7. Doi: 10.4103/0971-7749.187971
19. Gupta S, Mittal S, Kumar A, Singh KD. Selfassessment of hearing quality and noise-related attitudes among traffic policemen of Patiala, India. Int J Prev Med. 2014; 5: 511-5. PMID: 24829741

20. Khan HU, Khan S, Ali SI. Evaluation of road traffic noise pollution in Quetta (Pakistan). Am J Modern $\begin{array}{llll}\text { Phys. 2014; 3(2): 29-36. Doi: } & \end{array}$ 10.11648/j.ajmp.20140302.11

21. Khan MW, Memon MA, Khan MN, Khan MM. Traffic noise pollution in Karachi, Pakistan. JLUMHS. 2010; 9(3): 114-20.

22. Gupta M, Khajuria V, Manhas M, Gupta KL, Onkar S. Pattern of noise induced hearing loss and its relation with duration of exposure in traffic police personnel. Indian J Comm Health. 2015; 27(2): 276-80.

23. Venkatappa KG, Shankar V, Sparshadeep EM. Effect of road traffic noise on auditory threshold in traffic policemen. Int J Curr Res Biol Med. 2018; 3(6): 12-7. Doi: 10.22192/ijcrbm.2018.03.06.004

24. Traffic Police Information, CPLC Lahore, Home Department, Govt. of Punjab, 2010.

25. Tabraiz S, Ahmad S, Shehzadi I, Asif MB. Study of physio-psychological effects on traffic wardens due to traffic noise pollution; exposure-effect relation. Journal of environmental health science and engineering. 2015; 13(1): 30. Doi: 10.1186/s40201015-0187-x

26. Sreenivasulu M. Survey and cross-sectional study on noise induced hearing loss of police constables and officers working in heavy traffic areas-an Indian perspective. TJPRC: IJOHNS. 2016; 1(2): 17-20. TJPRC:

IJOHNSDEC20165 